\title{
Komputasi Data Isotermal Reaksi Pertukaran Ion
}

\author{
${ }^{1}$ Sumarbagiono, ${ }^{2}$ Thamzil Las*, ${ }^{1}$ Husen Zamroni, ${ }^{3}$ Ayudhya SMM \\ ${ }^{1)}$ Pusat Teknologi Limbah Radioaktif (PTLR) Badan Tenaga Nuklir Nasional \\ Pasar Jum'at Jakarta Selatan \\ ${ }^{2)}$ Program Studi Kimia FST UIN Syarif Hidayullah Jakarta \\ ${ }^{3)}$ Badan Meteorologi Klimatologi dan Geofisika Jakarta
}

\begin{abstract}
Abstrak
Sebagian besar data penelitian yang masih bersifat teknis perlu dievaluasi lebih lanjut dengan menggunakan metode komputasi Data Isotermal Reaksi Pertukaran Ion dalam proses penyerapan logam berat dan radionukleotida oleh material sorben dari limbah cair. Melalui perhitungan Konstanta Kesetimbangan (Ka) dan Kuotisi Kielland diperoleh nilai entropi dan entalpi yang dapat digunakan untuk mengetahui selektifitas unsur yang teradsorsi dalam zeolit. Program Kielland dengan menggunakan Delphi 5 dapat digunakan secara praktis oleh para peneliti untuk menganalisa data isothermal pertukaran ion dari reaksi kesetimbangan dengan menghasilkan data yang lebih baik.
\end{abstract}

Kata Kunci : Komputasi, Data Isotermal, Reaksi Pertukaran Ion

\begin{abstract}
Most of experiment data are in raw data, which is need to analyses through the data reduction of computer for isotherms data of ion exchange in the process of separation of trace element and radionuclides from liquid wastes. The calculation of equilibrium constants, Kielland quotient, Kc and Gibbs energy are reached to calculated the entropy and enthalpy which is useful to identify the selectivities of element onto the zeolite. The program of computer using Delphi 5, are used for evaluate these isothermal data with good result and practicable to the researcher.
\end{abstract}

Keywords : Computation, Isothermal Data, Ion exchange

\section{PENDAHULUAN}

Zeolit adalah material penukar ion (ionexchange properties) disebabkan atom $\mathrm{Al}^{+3}$ tersubtitusi oleh atom $\mathrm{Si}^{+4}$. Muatan negatif pada atom $\mathrm{Al}$ ini dapat dinetralkan pada proses pertukaran ion dengan kation alkali, alkali tanah dan logam berat misalnya, $\mathrm{Na}, \mathrm{K}, \mathrm{Ca}, \mathrm{Mg}, \mathrm{Pb}, \mathrm{Ni}$, dan sebagainya $(1,2)$.

Pada proses pertukaran ion pada zeolit, reaksi terjadi secara reversibel dalam fase cair dengan material zeolit pada fase padat dan reaksi ini terjadi sesuai dengan stoikiometri reaksi pertukaran kation.

Mekanisme reaksi pertukaran ion dari zeolit, dapat dipelajari melalui reaksi kesetimbangan dengan menentukan selektivitas, Energy Gibbs, enthalpi dan entropi

Untuk itu dilakukan pengolahan data isotermal dari suatu reaksi pertukaran ion dari dua fase, cair dan padat dengan menggunakan berbagai konstanta termodinamika melalui persamaan yang telah didapatkan oleh Guggenheim dan Glueckauf diantaranya dengan menghitung konstanta kesetimbangan (Ka) suatu reaksi pertukaran ion dalam fase cair.

Oleh sebab itu perlu dilakukan evaluasi dan perhitungan $\mathrm{Ka}$ dari data isotermal yang diperoleh dari percobaaan terdahulu.

Nilai Ka yang telah dikoreksi dengan Kc (Kielland quotion) dapat digunakan untuk menentukan keselektifan dua atau multi-kation terhadap material penukar ion dimana pada 
penelitian ini digunakan zeolit dengan jenis klinoptilolit (4).

Diharapkan dari penelitian ini diperoleh program perhitungan konstanta kesetimbangan , $\mathrm{Ka}$ untuk reaksi Cs dengan $\mathrm{Na}, \mathrm{K}, \mathrm{Ca}$, dan $\mathrm{Mg}$ Zeolit.

\section{Dasar teori dan Komputasi}

Reaksi pertukaran ion umumnya berlangsung secara bolak balik (reversible), dan terjadi pada dua fase yang berbeda yaitu fase cair dan padat $(4,5,6)$.

$$
{ }_{z B} A^{z A+}+{ }_{z A} B^{2 B+} \rightarrow{ }_{z B} A^{z B+}+{ }_{z A} B^{2 A+}
$$
$(\mathrm{s})$
(C)
(c)
(S)

Dalam reaksi (1) di atas, pertukaran ion $\mathrm{A}^{\mathrm{ZA}+}$ (counter ion) dalam fase cair terjadi dengan ion $\mathrm{B}^{+}$dalam fase padat dalam hal ini adalah zeolit. zA dan zB adalah valensi dari kation $\mathrm{A}$ and $\mathrm{B}, \mathrm{s}$ adalah fase cair dan $\mathrm{c}$ adalah fase padat. Ion A disebut juga sebagai "exchangeable ion" yang dapat dipertukarkan dengan ion lain.

Perumusan model matematik data isothermal ekuivalen fraksi kation A sebagai "exchangeable cation atau counter ion dalam larutan adalah :

$$
A s=\frac{Z_{A} m_{A}}{Z_{A} M_{A}}
$$

dan

$$
A Z=\frac{Z A M A}{Z_{A} M_{A}+Z_{B} M_{B}}=\frac{Z_{A} M_{A}}{C E C}
$$

$\mathrm{m}_{\mathrm{A}, \mathrm{B}}$ dan $\mathrm{M}_{\mathrm{A}, \mathrm{B}}$ adalah molaritas (mol/l atau $\mathrm{mol} / \mathrm{kg}$ ) dari kation A dan B dalam fase cair dan fase padat, sedangkan CEC adalah kapasitas tukar kation (eq $\mathrm{Kg}^{-1}$ ) material penukar ion kering atau meq/gr material penukar ion.

Dalam pertukaran dua kation total normalitas adalah :

$$
T N=Z_{A} M_{A}+Z_{B} M_{B}
$$

Bila kesetimbangan tercapai, konsentrasi kation A dan B dalam fase cair atau padat tidak berubah terhadap waktu. Fraksi ekivalen kation A dalam fase padat (Ac) dinyatakan sebagai $\mathrm{Ac}=$ jumlah eq ion $\mathrm{A}$ dalam fase padat/ jumlah total ion A dalam fase padat.

Koefisien selektivitas atau faktor pemisahan (separation factor) :

$$
\alpha=K_{m}{ }^{\left(1 / Z_{A}\right)}\left(A_{Z} / m_{A}\right)^{\left(Z_{A}-Z_{B} / Z_{A}\right)}
$$

Km adalah :

$$
K_{m}=\frac{A_{z}^{Z_{B}} m_{B}^{Z_{A}}}{B_{z}^{Z_{A}} m_{A}^{Z_{B}}}
$$

Kielland quotient $(\mathrm{Kc})$ sebagai berikut :

$$
\begin{gathered}
K_{C}=\frac{A_{z}^{Z_{B}} m_{B}^{{ }^{Z_{A}}} \Gamma}{B_{z}^{Z_{A}} m_{A}{ }^{Z_{B}}} \\
\ln K a=(Z B-Z A)+\int \ln K c d A z \\
\Delta G^{\circ}=\frac{-R T}{Z_{A} Z_{B}} \ln K a
\end{gathered}
$$

Jika $\Delta \mathrm{G}=0$ maka reaksi dalam keadaan setimbang, bila negatif reaksi berlangsung ke kanan, dan bila positif berlangsung kearah kiri. Selanjutnya Entalphi $(\Delta \mathrm{H})$ dan Entropi $(\Delta \mathrm{S})$ dapat pula dihitung.

$$
\Delta H=\left(\frac{R T^{2}}{Z_{A} Z_{B}}\right) d \ln \left(\frac{K a}{d T}\right)
$$

dan

$$
\Delta S=\left(\frac{\Delta H-\Delta G^{\circ}}{T}\right)
$$

\section{METODE PENELITIAN}

Penelitian dilakukan melalui program Komputer dan pemilihan input data berupa : 
1. Parameter Debye-Huckel untuk Garam AX dan $\mathrm{BX}$ dalam program ditulis $\mathrm{AA}, \mathrm{AB}, \mathrm{BA}$ dan BB untuk temperatur tertentu yang diperoleh dari literatur

2. Muatan ion $\mathrm{A}, \mathrm{B}$ dan $\mathrm{X}$, yaitu $\mathrm{z}^{\mathrm{A+}}, \mathrm{z}^{\mathrm{B}+}$ dan $\mathrm{z}^{\mathrm{X}-}$

3. Total normalitas larutanTN

4. Jumlah percobaan atau titik isotermal(N) dengan berbagai fraksi dalam kation dalam larutan dan zeolit, AS dan AC)

5. Polinomial (degree 1-6) yang digunakan untuk perhitungan $\mathrm{Ka}$.

\section{Algoritma Program (4)}

1. Mencatat Input Program Parameter DebyeHuckel untuk :

- Incoming cation (AA \& AB)

- Outgoing cation (BA \& BB)

Muatan :

- Incoming cation (ZA)

- Outgoing cation (ZB)

- Common cation (ZX)

Normalitas total (TN)

Titik-titik Isothermal (AC, AS)

2. Menghitung Molaritas Anion (MX) $\mathrm{MX}:=\mathrm{TN} / Z \mathrm{X}$;

3. Menghitung Parameter Thermodinamik untuk setiap titik Isotermal

for $\mathrm{N}:=1$ to ITEMS do

begin

$\mathrm{AC}:=\mathrm{X}[\mathrm{N}] ; \mathrm{BC}:=1-\mathrm{AC}$;

ASO:=Y[N]; BS:=1-AS0;

$\mathrm{MA}:=\mathrm{AS} 0 * \mathrm{TN} / \mathrm{ZA} ; \mathrm{MB}:=\mathrm{BS} * \mathrm{TN} / \mathrm{ZB}$;

$\mathrm{n}_{1}:=\operatorname{POWER}(\mathrm{AC}, \mathrm{ZB})$;

$\mathrm{n}_{2}:=$ POWER(MB,ZA);

$\mathrm{n} 3:=$ POWER(BC,ZA);

$\mathrm{n}_{4}:=$ POWER(MA,ZB);

$\mathrm{KM}:=\mathrm{n} 1 *_{\mathrm{n} 2} /\left(\mathrm{n} 3 *^{*} \mathrm{n} 4\right)$;

// Model Debye-Huckel

// untuk Menghitung Ionic strength (ION)

$\mathrm{ION}:=0.5^{*}\left(\mathrm{MA} * \mathrm{ZA} * \mathrm{ZA}+\mathrm{MB} * \mathrm{ZB} * \mathrm{ZB}+\mathrm{MX}^{*}\right.$ $\mathrm{ZX} * \mathrm{ZX})$;

//Hitung solution phase activity coefficients untuk // incoming dan outgoing cation (LOGAM1, LOGAM2)

$\mathrm{RI}:=\mathrm{SQRT}(\mathrm{ION})$;
$\mathrm{P} 1:=(-0.5155) *(\mathrm{ZA} * \mathrm{ZX}) * \mathrm{RI}$

$\mathrm{P} 2:=(3291000000) * \mathrm{AA} * \mathrm{RI}$

$\mathrm{Q} 1:=(-0.5155) *(\mathrm{ZB} * \mathrm{ZX}) * \mathrm{RI}$;

$\mathrm{Q} 2:=(3291000000) * \mathrm{BA} * \mathrm{RI}$;

LOGAM1:=P1/(1.0+P2)+AB*ION;

LOGAM2:=Q1/(1.0+Q2)+BB*ION;

// Model Glueckauf

// untuk Menghitung corrected solution phase activity coefficients untuk

// incoming dan outgoing cation (LOGAM3, LOGAM4)

$\mathrm{K} 1:=\mathrm{ZB} *(2.0 * \mathrm{ZB}-\mathrm{ZA}+\mathrm{ZX})$;

$\mathrm{K} 2:=(\mathrm{ZA} *(\mathrm{ZB}+\mathrm{ZX}) *(\mathrm{ZB}+\mathrm{ZX})) /(\mathrm{ZA}+\mathrm{ZX})$;

$\mathrm{K} 3:=(0.5 * \mathrm{ZA} * \mathrm{ZB} * \mathrm{ZX} *(\mathrm{ZA}-\mathrm{ZB}) *(\mathrm{ZA}-$

$\mathrm{ZB})) /(\mathrm{ZA}+\mathrm{ZX})$;

$\mathrm{K} 4:=\mathrm{ZA} *(2 * \mathrm{ZA}-\mathrm{ZB}+\mathrm{ZX})$;

$\mathrm{K} 5:=(\mathrm{ZB} *(\mathrm{ZA}+\mathrm{ZX}) *(\mathrm{ZA}+\mathrm{ZX})) /(\mathrm{ZB}+\mathrm{ZX})$;

$\mathrm{K} 6:=(0.5 * \mathrm{ZA} * \mathrm{ZB} * \mathrm{ZX} *(\mathrm{ZB}-\mathrm{ZA}) *(\mathrm{ZB}-$

$\mathrm{ZA})) /(\mathrm{ZB}+\mathrm{ZX})$;

$\mathrm{Y} 1:=\mathrm{MA} /(4.0 * \mathrm{ION}) ; \mathrm{Y} 2:=\mathrm{K} 4 * \mathrm{LOGAM} 2$;

$\mathrm{Y} 3:=\mathrm{K} 5 *$ LOGAM 1 ;

$\mathrm{Y} 4:=\mathrm{K} 6 /(1.0+1 /(\mathrm{SQRT}(\mathrm{ION})))$;

$\mathrm{Z} 1:=\mathrm{MB} /(4.0 * \mathrm{ION}) ; \quad \mathrm{Z} 2:=\mathrm{K} 1 *$ LOGAM1;

$\mathrm{Z3}:=\mathrm{K} 2 *$ LOGAM2;

$\mathrm{Z} 4:=\mathrm{K} 3 /(1.0+1 /(\mathrm{SQRT}(\mathrm{ION})))$;

LOGAM3:=LOGAM1-(Z1*(Z2-Z3-Z4));

LOGAM4:=LOGAM2-(Y1*(Y2-Y3-Y4));

// Hitung Gamma

$\mathrm{X} 1:=\mathrm{ZA} *(\mathrm{ZB}+\mathrm{ZX}) *$ LOGAM4;

$\mathrm{X} 2:=\mathrm{ZB} *(\mathrm{ZA}+\mathrm{ZX}) * \mathrm{LOGAM} 3$;

LOGAM A: $=(\mathrm{X} 1-\mathrm{X} 2) / \mathrm{ZX}$;

GAMA:= POWER(10,LOGAMA);

// Hitung Kielland coefficients (KC) dan

// selectivity coefficients (ALPHA)

$\mathrm{KC}:=\mathrm{KM}^{*} \mathrm{GAMA}$; LOGKC: $=\operatorname{Ln}(\mathrm{KC})$;

ALPHA: $=(\mathrm{AC} * \mathrm{MB}) /(\mathrm{BC} * \mathrm{MA})$;

LNKC $[\mathrm{N}]:=$ LOGKC;

$\mathrm{ACC}[\mathrm{N}]:=\mathrm{AC}$;

$\mathrm{ASS}[\mathrm{N}]:=\mathrm{AS} 0$;

end;

4. Menjalankan Rutin Curve Fitting untuk memprediksi fungsi $\mathrm{Ln}(\mathrm{KC})$

PolyFit (xcf, ycf, acoef[sTerms], sig[sTerms], correl[sTerms], nPoints, sTerms);

5. Menghitung Integral dari fungsi hasil curve fitting antara 0 and 1

ss: $=\operatorname{acoef}[0]+\operatorname{acoef}[1] / 2+\operatorname{acoef}[2] / 3+$ acoef [3]/4+ acoef [4]/5+ acoef [5]/6+ acoef $[6] / 7$; 
6. Menghitung Ln(KA) dan Delta $\mathrm{G}$

LNKA:=ZB-ZA+ss;

DELTAG: $=$ -

8.314*298*LNKA/(ZA*ZB*1000);

\section{HASIL DAN PEMBAHASAN}

Ac, fraksi nuklida Cs-137 dalam zeolit K-MDL, dan As adalah fraksi Cs-137 dalam larutan dengan total normalitas $0,01 \mathrm{~N}$ dengan 13 variasi konsentrasi yang diperoleh dari percobaan "batch" pada temperatur kamar, dapat dilihat pada tabel 1

Tabel 1. Input dan hasil perhitungan fiting As calc

\begin{tabular}{|c|c|c|c|c|}
\hline No & Ac & AS & As calc & Residual \\
\hline 1 & 0,0369 & 0,0092 & 0,0418 & 0,0325 \\
2 & 0,0985 & 0,0308 & 0,0165 & $-0,0143$ \\
3 & 0,1385 & 0,0461 & 0,0204 & $-0,0257$ \\
4 & 0,1785 & 0,0677 & 0,0405 & $-0,0272$ \\
5 & 0,2277 & 0,0862 & 0,0872 & 0,0010 \\
6 & 0,2862 & 0,1846 & 0,1743 & $-0,0103$ \\
7 & 0,3477 & 0,2431 & 0,3030 & 0,0599 \\
8 & 0,3969 & 0,3692 & 0,04334 & 0,0642 \\
9 & 0,4154 & 0,4677 & 0,4886 & 0,0209 \\
10 & 0,4369 & 0,5538 & 0,5573 & 0,0034 \\
11 & 0,4431 & 0,6892 & 0,05778 & $-0,1115$ \\
12 & 0,5046 & 0,8215 & 0,8035 & $-0,0180$ \\
13 & 0,5323 & 0,8923 & 0,9174 & 0,0251 \\
\hline
\end{tabular}

Selanjutnya berdasarkan tabel di atas dibuat kurva fiting untuk pangkat $2 \mathrm{AC}$ vs. AS seperti terlihat pada gambar di bawah :



Gambar 1. Kurva fiting untuk $\mathrm{AC}^{2}$ vs. $\mathrm{AS}$
Mengamati tipe kurva tersebut yang melengkung ke arah Ac, suatu indikasi bahwa zeolit MDL cenderung menyerap Cs-137 atau zeolit selektif terhadap Cs ( dibandingkan terhadap K).

\section{Aplikasi Program}

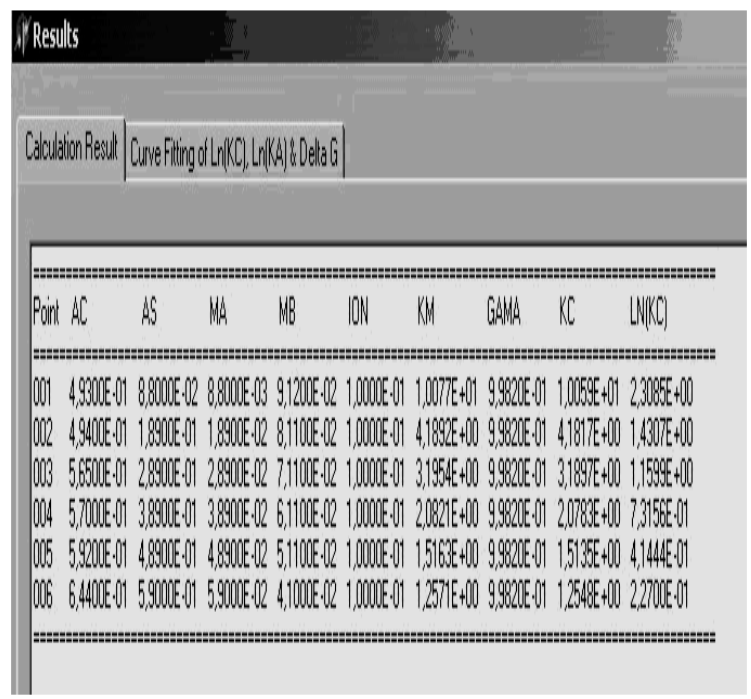

Gambar 2. Hasil Perhitungan $\operatorname{Ln}(\mathrm{Kc})$

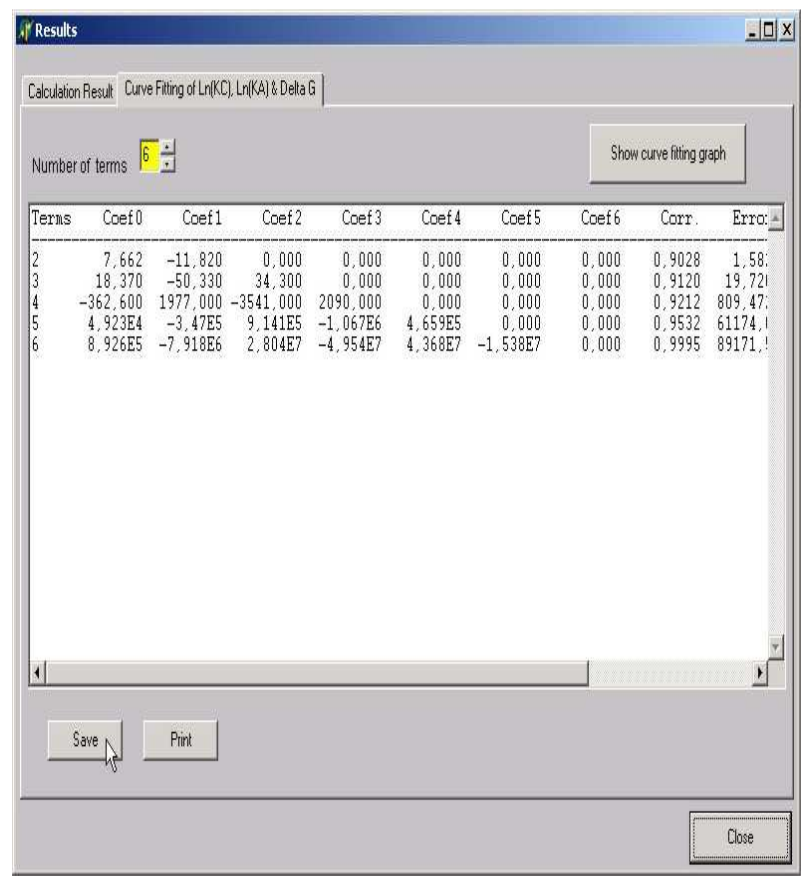

Gambar 3. Hasil Curve Fitting Ln(kc 


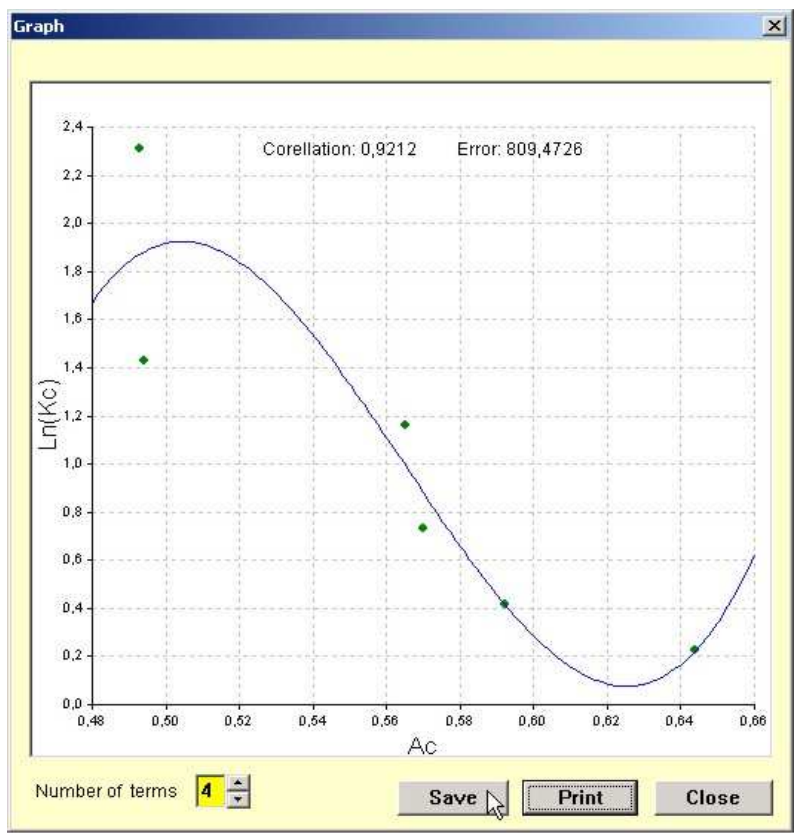

Gambar 4. Contoh Grafik Hasil Curve Fitting $\mathrm{Ln}(\mathrm{kc})$ pangkat 3 (3).

\section{KESIMPULAN}

Program ini merupakan salah satu cara pemecahan persoalan selektivitas kation yang dalam proses penukar ion melibatkan berbagai jenis kation dimana satu sama lain berkompetisi.

Dengan menghitung $\Delta \mathrm{G}$, maka percobaan cukup dilakukan dengan cara sederhana dengan mencampurkan material penukar ion atau adsorben dengan cairan limbah secara "batch" (bukan dengan teknik kolom) sehingga terjadi pemekatan kontaminan dalam penukar ion.

Pengukuran dengan $\Delta \mathrm{G}$ telah memberikan penghematan waktu untuk merancang penelitian skala besar menggunakan data-data hasil komputasi dengan syarat kepekatan cairan di bawah $0,1 \mathrm{~N}$.

\section{DAFTAR PUSTAKA}

1. Smith, J.V., 1988, Zeolites, 4:309.

2. Dyer A, 1984, Chemistry and Industry, $7: 241$.

3. Paterson R., 1969, "An Introduction to Ion Exchange ", Heyden \& Son Ltd, AERE, Harwell.
4. Thamzil Las, 1989, “Use of Zeolite For Nuclear Waste Treatment", $\mathrm{PhD}$ Thesis, University of Salfoord, Manchester, UK.

5. Annonim, 1976, "The Theory and Practice of Ion Exchange", Int. Conf. University of Cambridge , Society of Chemical Industry", London.

6. Helfferich, F., 1962, " Ion Exchange ", McGraw-Hill, New York, USA. 